(2) Open Access Full Text Article

REVIEW

\title{
Amyotrophic lateral sclerosis: update and new developments
}

This article was published in the following Dove Press journal:

Degenerative Neurological and Neuromuscular Disease

23 February 2012

Number of times this article has been viewed

\author{
Ashley J Pratt ${ }^{1}$ \\ Elizabeth D Getzoff' \\ J Jefferson P Perry ${ }^{1,2}$ \\ 'Department of Molecular Biology \\ and The Skaggs Institute for Chemical \\ Biology, The Scripps Research \\ Institute, La Jolla, CA 92037, USA; \\ ${ }^{2}$ The School of Biotechnology, Amrita \\ University, Kollam, Kerala 690525, \\ India
}

\begin{abstract}
Amyotrophic lateral sclerosis (ALS) is the most common form of motor neuron disease. It is typically characterized by adult-onset degeneration of the upper and lower motor neurons, and is usually fatal within a few years of onset. A subset of ALS patients has an inherited form of the disease, and a few of the known mutant genes identified in familial cases have also been found in sporadic forms of ALS. Precisely how the diverse ALS-linked gene products dictate the course of the disease, resulting in compromised voluntary muscular ability, is not entirely known. This review addresses the major advances that are being made in our understanding of the molecular mechanisms giving rise to the disease, which may eventually translate into new treatment options.
\end{abstract}

Keywords: amyotrophic lateral sclerosis, neurodegeneration, motor neuron disease, genetics, aging

\section{Introduction}

Amyotrophic lateral sclerosis (ALS), also known as Charcot's disease or Lou Gehrig's disease is the most widespread type of motor neuron disease. Striking later in life, the disease causes degeneration of motor neurons and consequently progressive atrophy of associated muscle tissues and supporting cells. Unlike similar motor neuron diseases that primarily affect only a single subgroup of neurons (eg, Primary Muscular Atrophy or Primary Lateral Sclerosis), ALS patients typically have both lower motor neuron (LMN) and upper motor neuron (UMN) involvement. The symptoms of ALS commonly are muscle weakness and wasting, especially in the limbs, cramps, twitching, and difficulties in speaking. The lifetime risk of acquiring ALS by age 70 is between 1 in 400 and 1 in $1000,{ }^{1}$ and in general, ALS individuals succumb to the disease within 2-3 years due to respiratory failure.

A growing number of ALS-causing genes have been identified recently and are now under investigation, providing promise for increased understanding of the etiology of the disease. SOD1, encoding the highly conserved, cytosolic antioxidant enzyme $\mathrm{Cu}, \mathrm{Zn}$-superoxide dismutase ( $\mathrm{Cu}, \mathrm{ZnSOD})$, was the first such gene to be identified with ALS. ${ }^{2,3}$ SOD1 mutations are common in both familial ALS (FALS) and sporadic ALS (SALS), and have been studied in the most depth. Other genes such as $O P T N^{4}$ or $T A R D B P, F U S$, and $A N G$ (involved in RNA metabolism) ${ }^{5}$ were later identified as causative factors in both FALS and SALS. Suggestive of proteolytic disfunction, UBQLN2 was recently implicated in ALS, ${ }^{6,7}$ and very recently, nucleotide repeat expansions in C9ORF 72, ${ }^{8-10}$ were found to comprise the largest fraction of ALS-causing mutations
Correspondence: J Perry

The Scripps Research Institute, 10550 N. Torrey Pines Road, MB-4, La Jolla, CA 92037, USA

Tel +l 8587842284

Fax+l 8587842289

Email jjperry@scripps.edu
Degenerative Neurological and Neuromuscular Disease 20I2:2 I-14

(C) 2012 Pratt et al, publisher and licensee Dove Medical Press Ltd. This is an Open Access article which permits unrestricted noncommercial use, provided the original work is properly cited.
Dovepress

http://dx.doi.org//0.2/47/DNND.S19803 
known to date. The present era is an exciting time for ALS research with the major challenge of understanding how these distinct, underlying triggers lead to a common aberrant cellular dyshomeostasis phenotype, resulting in toxic protein aggregates, neuronal death, and subsequently muscle atrophy that ultimately paralyzes the ALS patient.

Only one drug, riluzole, has been approved to treat ALS, which typically provides a meager gain of a few months of survival. ${ }^{11}$ With advances in diagnostics and personalized medicine, however, future ALS patients will hopefully find improved treatment regimes to follow for their specific ALS manifestations. In this review, we will focus on the recent breakthroughs that will likely provide new avenues to reach this outcome. These include increased understanding of the basic biology of ALS and progress toward upcoming therapeutics in development.

\section{Diagnosis of ALS Epidemiology}

Worldwide, the incidence rate of ALS varies from approximately $0.3-2.5$ cases per year per 100,000 persons. $^{12}$ Five percent or greater of all cases run in families (FALS), ${ }^{13}$ with a range from $2 \%-15 \%$ in different populations, ${ }^{14}$ although regional and/or ethnic variations in incidence ${ }^{15,16}$ and penetrance ${ }^{17}$ complicate the estimation, ${ }^{18}$ as do the organization of the studies themselves, being either populationor clinic-based. ${ }^{19}$ Aside from family history, the clinical presentation of FALS and SALS can be very similar. ${ }^{20}$ The onset for FALS is typically several years before that of SALS, although an exact age is difficult to estimate. In one study, for example, the mean FALS age was 48, as compared to 66 for a population-based group, ${ }^{21}$ whereas in another larger study the discrepancy, although still present, was not as large (52 versus 56, respectively). ${ }^{22}$ Typically, in SALS cases, but not always in FALS, ${ }^{21,22}$ males appear to predominate, ${ }^{23}$ but this may vary among ethnic backgrounds and may be trending toward equality with time. ${ }^{24}$ The higher incidence of ALS among war veterans and smokers, ${ }^{25-27}$ potentially accounts for the increased male risk, in addition to factors such as male hormones. ${ }^{28}$ Interestingly, a recent study suggested that a lower-than-average ratio of the index to ring finger is represented in ALS patients. ${ }^{29}$ This measurement (termed the 2D:4D ratio) is thought to reflect androgen exposure in the $\mathrm{womb}^{30,31}$ and therefore postulates a role for prenatal developmental factors in the disease. Sports (soccer and football) and sport-specific effects (soccer, but not basketball or cycling) $)^{32}$ have also been implicated in ALS disease development. ${ }^{25,33}$ Finally, higher body mass index (up to 30-35) was found to correlate to disease survival, ${ }^{34}$ possibly due to the common weight loss phenotype from muscle wasting associated with disease progression. An improved awareness of risk factors and trends for ALS might eventually establish better preventative measures or treatments, especially for those with a family history of the disease.

\section{Symptom presentation and examination}

No single test for diagnosing ALS exists; most cases are established based on symptom presentation, progression, and tests to eliminate overlapping conditions. ${ }^{35}$ ALS is typically characterized by combined symptoms of the UMNs and LMNs. The UMNs of the central nervous systems originate in the motor cortex or brainstem and relay motor information to the LMNs. The LMNs are located in the brainstem and spinal cord and relay impulses from the UMNs to the muscles at neuromuscular synapses to innervate skeletal muscles controlling the arms and legs. UMN symptoms include weakness, speech problems, overactive reflexes, spasticity, and inappropriate emotionality; LMN symptoms also include weakness, as well as decreased reflexes, cramps, twitching and muscle wasting. ${ }^{36,37}$ Disease onset usually begins in the limbs (termed spinal onset), although about a quarter of ALS patients have "bulbar" onset, ${ }^{38}$ the term describing the facial, mouth/jaw, and tongue muscles controlled by the "bulb," an early name for the lower brainstem. Associated with poorer prognosis, bulbar onset is more common in elderly patients and women. ${ }^{39,40}$ A hallmark of ALS is rapid progression, and over time most patients will display both spinal and bulbar features (including emotionality, yawning, jaw jerking, tongue twitching, wasting, drooling, and difficulties swallowing). The El Escorial Criteria are a set of guidelines for ALS diagnosis, frequently used to gauge clinical trial participation and clinical practice. In some cases, though, these criteria may be overly stringent when used in diagnosis. ${ }^{41}$

Diagnosis may be seen as a process of elimination, although family history can also be useful. The battery of tests performed, ie, blood tests, electromyography, magnetic resonance imaging, and nerve conduction studies, can aid in ruling out other conditions. ${ }^{42}$ For example, in some patients, creatine kinase activity may be slightly elevated. ${ }^{43}$ Cerebrospinal fluid (CSF) examination, on the other hand, is typically normal but can aid in diagnosing conditions such as multiple sclerosis. Furthermore, muscle biopsy can rule out inclusion body myositis. ${ }^{44}$ Indeed, a central challenge in ALS diagnosis is distinguishing the many mimics. 
These include injuries (eg, herniated disk, spinal compression, or heavy metal poisoning), cervical spondylosis, metabolic problems such as enzyme/vitamin deficiency (B-12 etc), copper deficiency or thyroid problems, stroke, myopathies or neuropathies, inclusion body myositis, infections such as Lyme or HIV, or diseases such as myasthenia gravis, syringomyelia, cancer, Kennedy's disease, Tay-Sachs diseases, or multiple sclerosis, among others. ${ }^{12,20,36,37,44-46}$ Misdiagnoses are in fact very common, ${ }^{20,47}$ about $10 \%$ of patients with other disorders are diagnosed erroneously with ALS. ${ }^{48,49}$ These findings may result in incorrect (potentially harmful) treatments, and delays in obtaining the necessary therapies and support and in seizing clinical trial opportunities.

Attempts to identify ALS-specific biomarkers may prove useful. For example, a study examining blood plasma found statistically significant distinctions in a panel of several hundred metabolites among ALS patients, allowing the authors to cleanly separate control patients from diseased patients (on taking or not taking riluzole), and even to sub-classify LMNaffected patients. ${ }^{50}$ Such efforts may eventually aid the clinician in more specifically diagnosing motor neuron disease.

\section{Pathophysiology Protein inclusions and cellular dyshomeostasis}

Typical hallmarks of ALS revealed from post-mortem examinations of patient brain and spinal cord sections are neuronal atrophy and the presence of cellular inclusions. Inclusions typical of affected cells include the small, cystatin- $\mathrm{C}$ and transferrin-immunoreactive Bunina bodies. ${ }^{51}$ Also very common are ubiquitinated cellular inclusions, most often skein-like or of the round Lewy-body hyaline variety. ${ }^{52}$ The presence of ubiquitin-reactive inclusions is consistent with a very recent study demonstrating that defects in the ubiquitin proteasome system may be a more generalized feature of ALS. ${ }^{6}$ Degenerative cellular abnormalities can afflict the motor cortex, the brainstem, the anterior horn of the spinal cord, the lateral and/or anterior corticospinal tracts. Distinct cellular inclusions, suggested by differential protein composition, are observed in ALS arising from different genetic backgrounds (discussed below).

Another common facet of ALS pathophysiology is irregular glutamate metabolism, targeted by riluzole, the only drug approved to treat ALS. ${ }^{53}$ Elevated synaptic glutamate can lead to excessive stimulation of glutamate receptors (eg, AMPA and NMDA) on the postsynaptic neuron, resulting in nerve damage and death through excitotoxicity.
Interestingly, the above-described features may also occur in the supporting glia, including astrocytes in which inclusions and downregulation of GLT-1 (also known as EAAT2) glutamate transporter were observed. ${ }^{54}$ Other relevant cellular abnormalities in ALS include an increase of p53-mediated apoptosis, impaired axonal transport, and cytoskeletal and mitochondrial dysfunction. ${ }^{55-58}$ Additionally, as disease symptoms appear at mid-to-late life, cumulative damage occurring through increased levels of oxidative stress may be a significant contributor to the disease. ${ }^{59} \mathrm{~A}$ recent study analyzing the CSF of ALS patients suggested distinct metabolic signatures discernible between SALS patients and those with SOD1 and non-SOD1 FALS. The metabolomes of SOD1 FALS patients were observed to be more homogeneous than those of non-SOD1 FALS patients, which were more homogeneous than those of SALS patients. ${ }^{60}$ These observations suggest that genetic contributions to the disease may influence ALS physiology.

\section{FALS and SALS genes}

Despite the identification of some ALS-causing genetic defects in individual families, ALS is not a single-pathway, single-gene condition. Therefore in recent years, high throughput, genome wide association studies have become a favored tactic for filling in the significant remaining space of unknown FALS-causing genes. ${ }^{61}$ Nonetheless, consistency in reproducing candidate genes had been a problem ${ }^{62}$ until the recent, notable exception of the C9ORF72 gene in the 9 p21 locus, ${ }^{8,9,63}$ a major ALS breakthrough. The disease subtypes associated with FALS mutations have been assigned designations of ALS1-ALS15 (Table 1). However, several known FALS mutations have now been documented in SALS cases, suggesting a broader role for these gene products in ALS pathogenesis. Although a variety of genes have been implicated in ALS (Table 1), we will focus on this subset of genes, in which genetic lesions can cause and contribute to both FALS and SALS.

\section{SOD 1}

The SOD1 gene encodes the cytosolic enzyme $\mathrm{Cu}, \mathrm{ZnSOD}$, which is conserved from bacteria to humans. $\mathrm{Cu}, \mathrm{ZnSOD}$ catalyzes the dismutation of the superoxide $\left(\mathrm{O}_{2}{ }^{-}\right)$radical anion, a toxic byproduct of cellular respiration, to produce molecular oxygen and hydrogen peroxide, ${ }^{64}$ with the toxicity of the latter being removed by conversion through a peroxidase or catalase. Over 150 SOD1 mutations (Figure 1) account for a significant fraction of FALS, and are typically present in about $20 \%$ of such cases (ranging from $2.5 \%-23.5 \%$ ), as 
Table I Common genes involved in ALS

\begin{tabular}{|c|c|c|c|c|c|}
\hline Gene & Locus & Protein & $\begin{array}{l}\text { Found in cellular } \\
\text { inclusions }\end{array}$ & ALS subtype & Other \\
\hline \multicolumn{6}{|c|}{ Autosomal dominant FALS genes also implicated in SALS } \\
\hline SODI & $21 q 22.1$ & $\mathrm{Cu}, \mathrm{Zn}$ superoxide dismutase (SOD) & + & ALSI & Can be recessive in FALS \\
\hline FUS & $|6 p| 1.2$ & Fused in sarcoma (FUS) & + & ALS6 & Can be recessive in FALS \\
\hline ANG & $|4 q| 1 . \mid$ & Angiogenin (ANG) & & ALS9 & $\begin{array}{l}\text { Autosomal Dominant } \\
\text { or Haploinsufficient }\end{array}$ \\
\hline TARDBP & Ip36.22 & $\begin{array}{l}\text { TAR DNA Binding Protein- } 43 \\
\text { (TDP-43) }\end{array}$ & + & ALSIO & \\
\hline OPTN & IOpI3 & Optineurin & + & ALSI2 & Can be recessive in FALS \\
\hline C9ORF72 & $9 p 21$ & C9ORF72 & $?$ & 'ALS-FTD' & Newly characterized \\
\hline \multicolumn{6}{|c|}{ Autosomal dominant FALS genes } \\
\hline ALS3 & $|8 q 2|$ & ALS3 & & ALS3 & \\
\hline SETX & $9 q 34.13$ & Senataxin & & ALS4 & Can cause juvenile onset \\
\hline ALS7 & $20 p \mid 3$ & ALS7 & & ALS7 & \\
\hline VAPB & $20 q \mid 3.33$ & VAMP-associated protein B & + & ALS8 & Can cause juvenile onset \\
\hline FIG4 & $6 q 21$ & Phosphoinositide 5-phosphatase & & ALSII & \\
\hline$V C P$ & $9 \mathrm{p} / 3.3$ & Valosin-containing protein & & ALSI4 & \\
\hline \multicolumn{6}{|c|}{ Autosomal recessive FALS genes } \\
\hline ALS2 & $2 q 33.1$ & Alsin & & ALS2 & Can cause juvenile onset \\
\hline SPGII & $15 q 15.1$ & Spatacsin & & ALS5 & Can cause juvenile onset \\
\hline \multicolumn{6}{|c|}{ X-linked dominant FALS gene } \\
\hline UBQLN2 & Xpll.2 & Ubiquilin-2 & + & ALSI5 & Can cause juvenile onset \\
\hline \multicolumn{6}{|c|}{ Other genes } \\
\hline ATXN2 & I2q24.I & Ataxin-2 & & ALSI3 & Increases ALS susceptibility \\
\hline
\end{tabular}

Note: Gene products discussed in the main text, as well as additional FALS and susceptibility genes and relevant characteristics are noted. Abbreviations: FALS, familial amyotrophic lateral sclerosis; SALS, sporadic amyotrophic lateral sclerosis.

well as in $0.44 \%$ to $7 \%$ of SALS cases. ${ }^{19,65}$ The majority of inherited SOD1 mutations are dominant, and individuals with two copies of a mutation may have much earlier onset. ${ }^{66,67}$ The common D90A SOD1 mutation is an exception that can be inherited in either a dominant or recessive fashion, as well as appearing sporadically. ${ }^{68,69}$

$S O D 1$ mutations do not appear to cause disease by a loss of function. For example, transgenic expression of SOD1 mutants in mice is pathogenic without altering enzyme activity. ${ }^{70}$ This is also evidenced by the fact that $\mathrm{Cu}, \mathrm{ZnSOD}$ deficient mice do not develop motor neuron disease ${ }^{71}$ and that mutations are not restricted to the active site of the enzyme. ${ }^{2}$ Instead, mutant $\mathrm{Cu}, \mathrm{ZnSODs}$ form toxic, misfolded species within neuronal and glial Lewy-body like inclusions ${ }^{72,73}$ that usually appear before symptom presentation. ${ }^{73,74}$ Within these aggregates, mutant $\mathrm{Cu}, \mathrm{ZnSOD}$ can be associated with heat shock protein Hsc70 $0^{75-77}$ or 14-3-3 proteins, suggesting in the latter case that sequestration of anti-apoptotic proteins could contribute to cell death. ${ }^{78}$ In a recent report, strong mutant $\mathrm{Cu}, \mathrm{ZnSOD}$ immuno-reactivity was observed in small, granular non-ubiquitin reactive inclusions that localize to the cytosol and/or lysosomes of FALS (SOD1 and non-SOD1) and non-SOD1 SALS patients. ${ }^{79}$ Also, Cu,ZnSOD-positive nuclear inclusions have been observed in spinal-cord derived glia from FALS and SALS patients. ${ }^{80}$ Therefore, $\mathrm{Cu}, \mathrm{ZnSOD}$ aggregates, found in tissues from distinct ALS patients, may be a component of diverse cellular inclusions in affected motor neurons and their supporting cells.

Detailed analyses of $\mathrm{Cu}, \mathrm{ZnSOD}$ structures and enzymatic mechanisms ${ }^{81,82}$ including comparisons to bacterial $\mathrm{Cu}_{\mathrm{ZnSOD}}{ }^{83}$ and the human mitochondrial MnSOD ${ }^{84-86}$ provided an informed foundation to evaluate the diverse mutations. ${ }^{2,87}$ To explain the complex effects of $\mathrm{Cu}, \mathrm{ZnSOD}$ mutations in ALS pathogenesis, we and others have proposed a framework destabilization hypothesis. ${ }^{87-89}$ In this hypothesis each of the diverse set of mutations can cause local unfolding events that contribute to a globally defective, self-aggregating protein, which can deleteriously co-aggregate with other cellular proteins. ${ }^{88}$ Such framework-destabilizing mutations are associated with other neurodegenerative and cancer prone diseases as typified by mutants of the XPD helicase. ${ }^{90}$ Several studies have attempted to characterize the aggregation propensity of mutant forms of $\mathrm{Cu}, \mathrm{ZnSOD}$ in vitro and in cultured cells, but a direct correlation between mutant protein stability and clinical phenotype has been elusive. ${ }^{91-94}$ This lack of correlation could be due to a multitude of contributing 


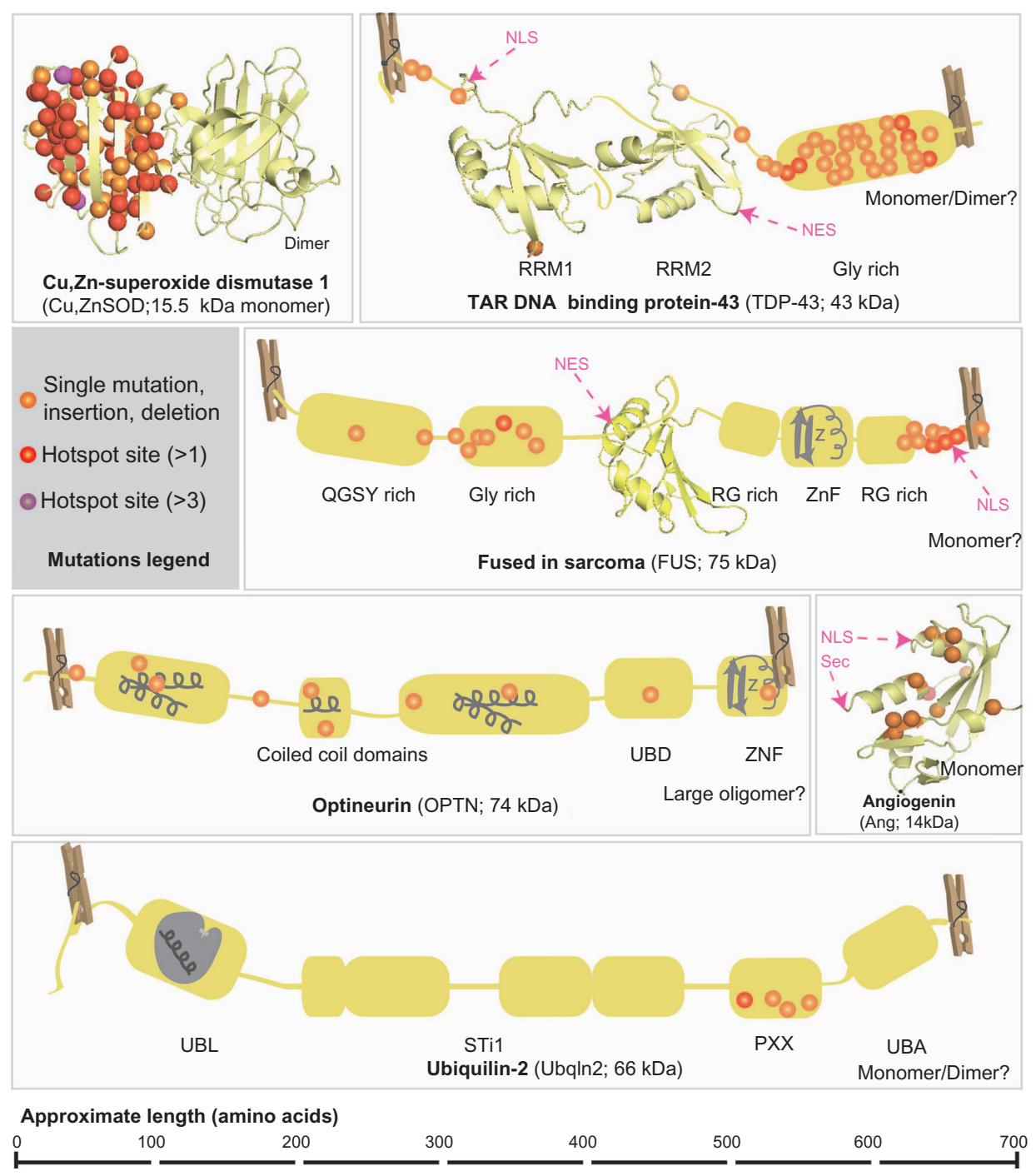

Figure I Known mutations in FALS and SALS-associated proteins.

Notes: Known mutations are mapped onto their corresponding proteins. Single mutations can include point mutations, premature stop codons, deletions, or insertions. For simplicity, one of the SOD dimers contains the mapped mutations. Structural and Domain Organization is indicated. Solved structures of domains or entire proteins are shown as ribbon diagrams: Cu,ZnSOD (IPU0); TDP-43 RRMI (ICQG); TDP-43 RRM2 (IWF0); FUS RRM (ILA6); Angiogenin (IBII). Clothespins indicate that the tertiary structure and inter-domain associations are not entirely known, so protein is stretched out to better show mutations sites. Schematic depictions of conserved domains without solved structures are shown in grey. Where applicable, known or putative oligomeric state and molecular weights are indicated.

Abbreviations: FALS, familial amyotrophic lateral sclerosis; SALS, sporadic amyotrophic lateral sclerosis; NLS, nuclear localization sequence; NES, nuclear export sequence; $\mathrm{Sec}$, cleaved signal sequence; RRM, RNA regnition motif; $\mathrm{X}$ rich, $\mathrm{X}$ (amino acid residue) rich motifs; UBD, ubiquitin binding domain; ZnF, zinc finger; UBL, ubiquitin like domain; STII, heat-shock-chaperonin-binding motifs; UBA, ubiquitin associated domain.

factors, ranging from important roles for metals in architectural stability, ${ }^{95}$ to aberrant oxidative modifications of the free cysteines, ${ }^{96,97}$ to anomalous interactions of mutant $\mathrm{Cu}, \mathrm{ZnSOD}$ with other cellular components. These components likely include proteins involved in stress responses (eg, Derlin-1, Rac-1 $)^{98,99}$ folding/maturation (eg, Hsc 70 and the $\mathrm{Cu}, \mathrm{ZnSOD}$ copper chaperone $)^{77,100}$ and vesicular transport associated proteins (eg, chromogranin, dynein heavy chain). ${ }^{101-103}$

\section{TARDBP}

The TARDBP gene encodes TAR DNA binding protein 43 (TDP-43), a modular DNA/RNA binding protein (Figure 1), localized to the cytosol and the nucleus, which is involved in splicing and transcriptional regulation. ${ }^{104}$ In vivo, TDP-43 depletion in mice resulted in mRNA reduction and splicing errors in many mRNA transcripts and a few non-coding RNAs, particularly long intron-containing transcripts. This suggests a broad role for TDP-43 in alternative splicing and prevention of nonsense-mediated decay of transcripts expressed in neurons. ${ }^{105}$ The nearly 40 mutations identified in the TARDBP gene encoding TDP-43 (Figure 1) may contribute to up to $6.5 \%$ of dominantly-inherited FALS cases, ${ }^{106,107}$ in addition to $0 \%-5 \%$ of sporadic cases. ${ }^{107-110} \mathrm{~A}$ reduced nuclear pool of TDP-43 is associated with some mutations, 
and cytoplasmic, ubiquitin-reactive hyperphosphorylated TDP-43 inclusions are observed in tissues from frontotemporal dementia (FTD) patients ${ }^{111,112}$ and in neuronal and glial tissues samples from SALS and Guam ALS patients. ${ }^{113}$ The inclusions commonly co-localize with ubiquitin and the protein p62. ${ }^{113}$ However, TDP-43 inclusions are not present in SOD1 FALS individuals ${ }^{114}$ (with the exception of one case $^{113}$ ) or FUS mutant patients. ${ }^{115}$

\section{FUS}

FUS encodes fused in sarcoma (FUS, also known as Translated in Liposarcoma, TLS), a modular nucleic acidassociated protein with many similarities to TDP-43, including conservation of protein domains (Figure 1), a role in RNA processing ${ }^{115}$ and localization in both the cytosol and nucleus in many cells. About 30 known FUS mutations account for approximately $3 \%-5 \%$ of FALS and $\sim 1 \%$ of SALS cases ${ }^{116,117}$ and all but the one known recessive variant, $\mathrm{H} 517 \mathrm{Q}^{118}$ cause a dominant phenotype. As with some TARDBP mutations, certain FUS mutations located near the nuclear localization sequence may shift the nuclear/cytoplasmic balance towards cytosolic. This imbalance occurs by impairing the transportinmediated import of FUS into the nucleus. ${ }^{119}$ FUS-reactive inclusions have been found in tissues from FUS mutant FALS patients but not in SOD1 mutant patients. ${ }^{115,117}$ Furthermore, although earlier studies failed to see FUS-immunoreactivity in SALS cases ${ }^{115}$ a more recent study did report FUS staining in inclusions from SALS patients. ${ }^{117}$ FUS inclusions are commonly seen in FTD patients, ${ }^{115,118,120}$ in addition to ALS patients, and these FUS-proteinopathy phenotypes might be distinguished through co-localization of other FUS family member proteins in FTD, but not in ALS. ${ }^{121}$ Furthermore, FUS and TDP-43 inclusion phenotypes are thought to be mutually exclusive in FTD, ${ }^{122,123}$ but this may not be the case in ALS; although TDP-43 reactivity was not observed in FUS ALS mutant tissues, ${ }^{115}$ FUS-reactivity was later reported in TDP-43 ALS mutant tissues. ${ }^{117}$

\section{OPTN}

A recent Italian study indicated that approximately $3.5 \%$ of SALS patients, in addition to $1.2 \%$ of FALS patients, had mutations in the OPTN gene, ${ }^{4}$ which encodes Optineurin. About a dozen mutations in OPTN can lead to ALS, with gain of function mutations dominant and loss of function mutations recessive. ${ }^{124,125}$ Optineurin is a multifunctional cytosolic and Golgi-associated coiled-coil domain-containing, ubiquitin-binding phosphoprotein (Figure 1). It is involved in vesicular trafficking and Golgi maintenance, signaling in the tumor-necrosis factor $\alpha / \mathrm{NF}-\kappa \mathrm{B}$ pathway, ${ }^{126} \mathrm{mGluR}$ signaling ${ }^{127,128}$ and autophagy. ${ }^{129}$ Optineurin has been shown to form homo-complexes and heteromultimerize with Rab8, myosin VI, and transferrin receptor proteins. In both FALS- and SALS-affected cells, Optineurin can co-localize in inclusion bodies with FUS ${ }^{130}$ and TDP-43, ${ }^{124}$ although the frequency of such inclusions was shown to be low in another study. ${ }^{131}$ Furthermore, Optineurin localization has been observed in basophilic inclusions from SOD1 FALS patient tissues, ${ }^{124}$ although conflictingly this co-localization was not observed in another study in patient-derived or mouse model tissues. ${ }^{132}$

\section{ANG}

Angiogenin (Ang, encoded by the $A N G$ gene), a small, hypoxia- and ischemia-inducible ${ }^{133}$ ribonuclease A (Figure 1) involved in angiogenesis, is mutated in a smaller number of FALS and SALS cases. ${ }^{134}$ Expressed in many tissues, including motor neurons, ${ }^{135}$ where it promotes cell survival, ${ }^{136}$ Ang is required for the VEGF-mediated stimulation of angiogenesis. ${ }^{137}$ Ang is secreted and taken up by effector cells via endocytosis, then translocated to the nucleus, to stimulate transcription of rRNA, among other roles. ${ }^{135}$ Due to loss of ribonuclease and/or nuclear translocation activity, ${ }^{135}$ $A N G$ mutations appear to attenuate angiogenesis although the protein stability is not compromised. ${ }^{138}$ Eighteen $A N G$ mutations, therefore, can cause a loss-of-function phenotype, with most $A N G$ ALS patients presenting with bulbar onset (discussed above). ${ }^{134}$

\section{UBQLN2}

$U B Q L N 2$, a gene on the $\mathrm{X}$-chromosome, was recently found to be causative for X-linked dominant FALS. ${ }^{6,139}$ In affected families, incomplete penetrance was noted in females, presumably due to $\mathrm{X}$-inactivation. The encoded ubiquilin-2 protein (Figure 1) normally performs effector functions in the ubiquitin proteasome pathway by tethering degradationtargeted proteins (through its C-terminal ubiquitin-associated domain) to the proteasome (through association with its N-terminal ubiquitin-like domain). The intervening regions within the protein are less well characterized, and include a PXX (proline-rich) domain, where five distinct mutations were found. In tissues derived from UBQLN2-mutant patients, ubiquitin-positive skein-like inclusions were also reactive for ubiquilin 2 . This phenotype was particularly notable in the spinal cord and hippocampus, correlating with the appearance of dementia in $20 \%$ of the X-linked ALS patients. Furthermore, these inclusions were also positive 
for TDP-43, FUS and OPTN, but not Cu,ZnSOD. Notably, ubiquilin-2 inclusion staining was present in all samples from a wide panel of genetically-distinct ALS patient tissues (sporadic, SOD1-mutant, TARDBP mutant, and non-FUS/ non-TARDBP/non-SOD1 FALS, and ALS with dementia) but not in non-ALS controls. ${ }^{6}$ Expression of mutant ubiquilin-2 protein significantly slowed down proteosomal degradation of a reporter substrate in Neuro-2a cells, ${ }^{6}$ suggesting a mechanistic contribution for these mutants. Unlike the other mutations described, those in the UBQLN2 gene have not yet been implicated in SALS. However, these findings suggest ubiquilin-2 could be generally relevant to ALS pathogenesis.

\section{C9ORF72}

Very recently, two independent research groups flagged C9ORF72 as the gene at locus 9p21 that was linked to dominant cases of ALS/FTD ${ }^{8,9}$ in previous genome-wide association studies. Strikingly, a substantial hexanucleotide repeat (GGGGCC) within an intron of this gene was identified in $24 \%-46 \%$ of FALS cases and $4 \%-21 \%$ of SALS cases, making this the most commonly mutated ALS gene. The expansion appeared to result in nuclear foci and directed preferential splicing of an alternatively spliced transcript. ${ }^{8}$ However, precisely how the aberrant RNA metabolism of C9ORF72 causes ALS is not yet known, and the protein, aside from nuclear localization, ${ }^{9}$ has no ascribed function. Interestingly, postmortem examination of several patients with the C9ORF72 hexanucleotide repeat, who exhibited ALS and FTD-like symptoms, also revealed neuronal TDP-43 inclusions. ${ }^{8}$

\section{Commonalities and crosstalk}

One puzzle for understanding ALS is that the known ALScausing gene products have diverse physiological functions. However, some common themes in pathogenesis are beginning to emerge. For example, RNA processing defects are visible in mutants of TARDBP, FUS, and $A N G$ (as well as a FALS gene called $S E T X) .{ }^{5}$ Nucleotide repeat expansions have also now been identified in C9ORF72 (and an ALSsusceptibility protein called Ataxin-2). ${ }^{140}$ Proteinacious cellular inclusions are also a common denominator in ALS patient-derived tissues; these can involve ubiquilin-2, as well as SOD, FUS, TDP-43, and/or optineurin. Interestingly however, different disease subtypes appear to reveal aggregates with distinct protein composition. Due to their roles in both ALS and FTD, TDP-43, FUS, OPTN, and ubiquilin-2 have been proposed to function in the context of a unified pathway. ${ }^{141}$ Thus, interactions among these components should be a focus for future research. Along these lines, a recent study in zebrafish found that the expression of human FUS could rescue the motor neuron phenotype associated with knockdown of TARDBP expression, whereas, conversely, TARDBP could not rescue $F U S$ knockdown, suggesting that $T A R D B P$ is genetically upstream of FUS. ${ }^{142}$ These results are consistent with a study showing that TDP-43 regulates the mRNA processing of FUS transcripts as well as its own. ${ }^{105}$

\section{Genetic overlap between ALS and other diseases}

Gene products whose mutations cause ALS have been implicated in other diseases. For example, FUS, TDP-43, ubiquilin-2, and/or optineurin-positive inclusions are found in many FTD patients, ${ }^{131,143}$ and C9ORF72 is implicated also in ALS/FTD. ${ }^{8,9}$ TDP-43-immunoreactivity is sometimes seen in hippocampal sclerosis, Pick's disease, and Alzheimer's disease (AD), and ubiquitin staining can occur in the latter disease. ${ }^{109}$ Likewise, optineurin has recently been implicated in $\mathrm{AD}$ due to its inclusion body staining in neurofibrillary tangles. ${ }^{144}$ Furthermore, optineurin interacts with the protein huntingtin, suggesting some role in Huntington's disease, ${ }^{145}$ and mutations in optineurin are associated with glaucoma ${ }^{146}$ and Paget's disease of the bone. ${ }^{147}$ The ubiquilin-1 paralog, with a domain structure similar to ubiquilin-2, is associated with AD. ${ }^{6}$ The 14-3-3 protein isoforms co-localized in $\mathrm{Cu}, \mathrm{ZnSOD}$ inclusions have also been found in a Parkinson's disease model, suggesting some commonalities in inclusion formation. ${ }^{148}$ Angiogenin has been implicated in a gamut of diseases, from cancers to diabetes, asthma, and heart disease. ${ }^{149}$ Finally, nucleotide repeats (as in C9ORF72) are known to cause a variety of neurodegerative diseases such as Huntington's disease, Fragile X-syndrome, Kennedy's disease and others. ${ }^{150}$ These observations underscore the need for meaningful synergistic collaborations among researchers studying these different complex diseases that often involve protein aggregation, allowing new insights to be compounded.

\section{Treatment of ALS}

The primary goal of ALS treatment is the inhibition of disease progression, although an important secondary consideration is the treatment of damage already done. Palliative care (eg, home care and hospice) remains a significant focus of the treatment program for the ALS patient. Non-invasive ventilation, for example, can improve the quality of life and extend survival in non-bulbar patients. ${ }^{151}$ A support team, and hospice care toward the end of life can help the ALS 
patient to prepare nutritive food that is easy to swallow, provide medications for muscle spasticity, weariness, sleep and depression, and adjust ventilators, enabling the patient to adjust to lifestyle limitations.

Although domestic alterations can provide significant relief to current patients, biochemical and pharmacological advances will drive forward better therapeutics. A panel of ALS biomarkers from non-invasive analyses would be a major gain not only in diagnosis and monitoring progression, but also in identifying affected biological pathways in ALS to target therapeutically. ${ }^{152}$ Multiple studies have sought to identify protein biomarkers for ALS, including increased blood or CSF levels of TDP-43, or the cysteine protease inhibitor cystatin C, or a skewed CSF ratio of phospho-neurofilament heavy chain to complement C3. ${ }^{153-156}$ Furthermore, the combined efforts of GC/MS (gas chromatography coupled to mass spectrometry), LC/MS (liquid chromatography coupled to mass spectrometry), and NMR (nuclear magnetic resonance) could potentially span the whole metabolome in identifying biomarker signatures. ${ }^{50,60}$ Better disease markers could reduce the long duration, averaging 14 months, between initial symptom presentation and diagnosis, ${ }^{47}$ helping to improve the disease trajectory. ${ }^{157}$ Such endeavors would also provide a platform for personalized medicine for ALS patients. At present, at least one clinical trial (NCT00677768) is being organized to analyze the blood and CSF of ALS patients for biological markers.

\section{Pharmacological interventions}

The only approved medicine to treat the general symptoms of ALS is the anti-excitotoxicity drug riluzole. ${ }^{158}$ The drug is thought to preserve motor neuron function by decreasing toxic glutamate levels at glutamatergic nerve terminals by (a) inactivating sodium channels, (b) inhibiting glutamate release, and (c) blocking postsynaptic actions of NMDA receptors. ${ }^{159}$ The safety and efficacy profiles for riluzole are better than those for other excitotoxicity drugs, but riluzole only increases the chance of an additional year of survival by about $9 \%$, typically prolonging survival for about 2-3 months. ${ }^{11}$ The drug serves to slightly preserve limb and bulbar function but actual muscle strength is typically not improved. ${ }^{11}$ Recently approved for treating purely the pseudobulbar affect symptoms less commonly observed in ALS patients is dual-acting dextromethorphan/quinine (sold as Neudexta ${ }^{\circledR}$; Avanir Pharmaceuticals, Aliso Viejo, CA). ${ }^{160}$ Like riluzole, dextromethorphan also inhibits glutamatergic signaling, and quinine helps to increase its bioavailability, providing modest benefit to a subset of patients. ${ }^{160}$
Promising new therapeutic developments, several of which are in late-phase clinical trials, may provide strides forward in treating ALS. One such drug in phase III clinical trials (NCT00349622) is the antibiotic ceftriaxone, used to treat pneumonia and bacterial meningitis. In ALS patients, ceftriaxone appears to upregulate the GLT-1 (EAAT2) glutamate transporter, potentially correcting cellular glutamate levels. ${ }^{161}$ Another potential treatment option is high-dose methylcobalamin (vitamine B-12), currently in phase II/III studies (NCT00444613 and NCT00445172) to determine safety and efficacy for long-term use in ALS. ${ }^{162}$ This compound was recently shown to reduce homocysteine (another excitatory amino acid)-mediated toxicity in NSC-34 cells. ${ }^{163}$ Finally, an antioxidant targeting the mitochondria is currently in phase III trials (NCT01281189), sponsored by Biogen Idec (Westin, MA) and Knopp Biosciences LLC (Pittsburgh, PA). This drug, dexpramipexole, ${ }^{164}$ is the $\mathrm{R}(+)$-isomer of the amino-benzothiazole drug pramipexole (currently approved to treat Parkinson's disease and restless legs syndrome). Dexpramipexole was well tolerated in phase II clinical trials, revealing positive trends in slowing function decline and improving survivability.

\section{SOD I-targeting therapies}

The establishment of mutant SOD1 transgenic mice in the late 1990s was a major breakthrough in the field, providing the first disease models for ALS. ${ }^{70}$ Now, about a dozen such SOD1 ALS mouse models exist. ${ }^{165}$ Other distinctive ALS models have been developed, ${ }^{166,167}$ including the newer TARDBP mouse models that similarly display ALS-like symptoms such as gait abnormalities, weight loss, and spasticity. ${ }^{104}$ However, the use of SOD1 mouse models has predominated much of the therapeutic progress, in part because $S O D 1$ represents a major disease target. For example, because the $S O D 1$ gene is predominately dispensible, ${ }^{71}$ reducing its expression and perturbing aggregation are favored strategies for treatment of ALS. These transgenic animals are appropriate models in many cases, and guidelines have been suggested for standardizing studies in SOD1 mice. ${ }^{168}$

Both small molecules and siRNAs are being explored to downregulate and diminish SOD levels. The hydroxylamine drug arimoclomol (Orphazyme) is currently in stage II/III clinical trials (NCT00706147). This compound induces a heat shock response that resulted in a decrease in ubiquitin-positive aggregates in G93A SOD1 mouse models, ${ }^{169}$ and is now being tested in SOD1 FALS patients. A free radical scavenger, edaravone (Mitsubishi Tanabe Pharma Corporation, Osaka, Japan) was recently found to ameliorate ALS symptoms and diminish SOD aggregate deposition in interior horn cells. Phase III clinical 
trials were recently completed (NCT00330681; NCT00424463; NCT00415519), with results pending publication, so the future success of the drug remains to be seen. Studies aimed at silencing SOD1 using siRNA-based strategies in mice have met with some success, ${ }^{170,171}$ although the inability of siRNA to pass the blood-brain barrier makes delivery a problem. Accordingly, Isis Pharmaceuticals Inc (Carlsbad, CA) has developed a CSFinfused delivery method for Isis-SOD1RX antisense oligos that recently were successful in animal models, ${ }^{172}$ and are now being examined in phase I clinical trials (NCT01041222). Finally, an approach aimed at prevention, which is in its infancy, is immunization against mutant $\mathrm{Cu}, \mathrm{ZnSOD}$ through vaccination with mutant $\mathrm{Cu}, \mathrm{ZnSOD}$ or metal-free $\mathrm{Cu}, \mathrm{ZnSOD}$ (exhibiting some similar pathogenic properties). ${ }^{173}$ As stable $\mathrm{Cu}, \mathrm{ZnSOD}$ polymers expected to break tolerance exist, ${ }^{174}$ and as antibodies favor reactions with more flexible regions, ${ }^{175,176}$ such antibody experiments may be promising.

A recent study used patient-derived progenitor cells to derive cultured astrocyte cell lines, and these were found to be toxic to motor neurons, via a mechanism involving secretion of uncharacterized factors. Interestingly, both FALS (mutant SOD1) and SALS-derived cells, but not non-ALS derived astrocyte cells, had common pathway changes (namely NF- $\mathrm{BB}$, MAPK, JNK, and $\mathrm{AKT}$ ), and knockdown of SOD1 rescued the motor neuron killing phenotype in four of six cell lines examined. ${ }^{177}$ This study interestingly reaffirms the use of SOD1-targeted therapeutics in the context of SALS (although the effects on other FALS genetic backgrounds were not tested) and also suggests that such cell cultures could prove useful for therapeutic screening in the absence of an all-encompassing ALS disease model. Indeed, a few years ago, astrocyte replenishment by injection of glial precursor cells in SOD1 model rats was found to prolong life and improve motor performance. ${ }^{178}$ Similarly, a phase I clinical trial (NCT01348451) aimed at spinal implantation of spinal cord-derived stem cells is being sponsored by Neuralstem Inc (Rockville, MD). This treatment previously extended the life of $S O D 1$ transgenic rats by 10 days, ${ }^{179}$ and provides the first regenerative medicine strategy for ALS.

\section{Future directions}

Where do we go from here? ALS was first described about 150 years ago ${ }^{180}$ and recent biotechnological advances have allowed researchers to begin pinpointing the precise genetics and pathological mechanisms behind the disease. Yet, many questions still remain: How do the distinct pathways involved in the disease overlap and converge to cause similar phenotypes? Can diagnostics improve to the point of early screening and detection? Arguably most importantly, how can we best treat individual patients? Fortunately, the complex nature of the disease also allows for many potential targets and means for therapeutic intervention.

The discovery of the role of SOD1 in ALS was a triggering event that significantly advanced our current understanding of the disease aided by the basic science of SOD structure and biochemistry. ${ }^{87,181}$ Although we now know that the mutant proteins aggregate, we are only starting to appreciate the key architectural features of the proteins involved in triggering this aggregation and its consequences. More recently, we have realized the significant contributions of TDP-43 and FUS in ALS and other degenerative diseases. ${ }^{182}$ Indeed, RNA metabolism appears to be a common thread. The recent identification of ubiquilin-2 as a co-immunolocalized component of ALS inclusions in a wide variety of ALS cell types has also been a major breakthrough in the field. ${ }^{6}$ Thus, follow-up work is now needed in order to determine the mechanism of this ubiquilin-mediated pathology, as well as its potential contributions to other ALS-linked pathways. Finally, determining the pathogenic mechanism of action of newly identified C9ORF72 repeats may prove extremely useful in understanding a significant majority of ALS cases, both sporadic and inherited. Newer disease models will undoubtedly play a significant role in facilitating these studies.

A critical element of progress in the ALS field will be the dissemination of genetic, epidemiologic, and therapeutic information. Fortunately, several helpful online databases and resource are now available, including the ALS online genetics database, ${ }^{183}$ the Genetic Association studies website, ${ }^{184}$ the ALS forum, ${ }^{185}$ and the Northeast ALS Consortium (NEALS). ${ }^{186}$ Outreach and social networking is provided by sites such as the Twitter-based ALS Untangled, ${ }^{187}$ which hosts a forum for patient conversations. These assets will increase awareness and discourse among ALS patients and drive future research collaborations.

\section{Conclusions}

Currently, ALS is an unrelenting and incurable neuromuscular disease that paralyzes its victims, eventually leaving them incapable of breathing. Gradually, thanks in part due to strides in molecular genetics, the mechanisms leading to aberrant cellular physiology and toxic inclusions are being sewn together. At present, therapeutic strategies aim to slow down the pace of the disease. Ultimately, however, future efforts will work to block the initial events leading to neuronal death. This will prevent damage to the patient's motor ability before it happens, stemming from earlier diagnosis and leading to better prognosis. 


\section{Acknowledgments}

This work was supported by NIH grant R03 AR059968 (to JJP) and NIH grant R01 GM39345 (to EDG). AJP is a predoctoral fellow of the National Science Foundation and the Skaggs Institute for Chemical Biology at the Scripps Research Institute.

\section{Disclosure}

The authors report no conflicts of interest in this work.

\section{References}

1. Wijesekera LC, Leigh PN. Amyotrophic lateral sclerosis. Orphanet $J$ Rare Dis. 2009;4:3.

2. Deng HX, Hentati A, Tainer JA, et al. Amyotrophic lateral sclerosis and structural defects in $\mathrm{Cu}, \mathrm{Zn}$ superoxide dismutase. Science. 1993;261(5124):1047-1051.

3. Rosen DR, Siddique T, Patterson D, et al. Mutations in $\mathrm{Cu} / \mathrm{Zn}$ superoxide dismutase gene are associated with familial amyotrophic lateral sclerosis. Nature. 1993;362(6415):59-62.

4. Del Bo R, Tiloca C, Pensato V, et al. Novel optineurin mutations in patients with familial and sporadic amyotrophic lateral sclerosis. J Neurol Neurosurg Psychiatry. 2011;82(11):1239-1243.

5. Strong MJ. The evidence for altered RNA metabolism in amyotrophic lateral sclerosis (ALS). J Neurol Sci. 2010;288(1-2):1-12.

6. Deng HX, Chen W, Hong ST, et al. Mutations in UBQLN2 cause dominant X-linked juvenile and adult-onset ALS and ALS/dementia. Nature. 2011;477(7363):211-215.

7. Daoud H, Rouleau GA. A role for ubiquilin 2 mutations in neurodegeneration. Nat Rev Neurol. 2011;7(11):599-600.

8. DeJesus-Hernandez M, Mackenzie IR, Boeve BF, et al. Expanded GGGGCC hexanucleotide repeat in noncoding region of C9ORF72 causes chromosome 9p-linked FTD and ALS. Neuron. 2011;72(2): 245-256.

9. Renton AE, Majounie E, Waite A, et al. A hexanucleotide repeat expansion in C9ORF72 is the cause of chromosome 9p21-Linked ALS-FTD. Neuron. 2011;72(2):245-268.

10. Wood H. A hexanucleotide repeat expansion in C9ORF72 links amyotrophic lateral sclerosis and frontotemporal dementia. Nat Rev Neurol. 2011;7(11):595.

11. Miller RG, Mitchell JD, Lyon M, Moore DH. Riluzole for amyotrophic lateral sclerosis (ALS)/motor neuron disease (MND). Cochrane Database Syst Rev. 2007;1:CD001447.

12. Sathasivam S. Motor neurondisease: clinical features, diagnosis, diagnostic pitfalls and prognostic markers. Singapore Med J. 2010;51(5):367-373.

13. Byrne SC, Hardiman O. Rate of familial amyotrophic lateral sclerosis: a systematic review and meta-analysis. Neurology. 2010;74(9):A56.

14. Conwit RA. Preventing familial ALS: a clinical trial may be feasible but is an efficacy trial warranted? J Neurol Sci. 2006;251(1-2):1-2.

15. Haberlandt WF. Genetic aspects of amyotrophic lateral sclerosis and progressive bulbar paralysis. Acta Genet Med Gemellol (Roma). $1959 ; 8: 369-374$.

16. Murros K, Fogelholm R. Amyotrophic lateral sclerosis in Middle-Finland: an epidemiological study. Acta Neurol Scand. 1983;67(1):41-47.

17. Williams DB, Floate DA, Leicester J. Familial motor neuron disease: differing penetrance in large pedigrees. J Neurol Sci. 1988;86(2-3):215-230.

18. Andersen PM, Al-Chalabi A. Clinical genetics of amyotrophic lateral sclerosis: what do we really know? Nat Rev Neurol. 2011;7(11): 603-615.

19. Andersen PM. Amyotrophic lateral sclerosis associated with mutations in the CuZn superoxide dismutase gene. Curr Neurol Neurosci Rep. 2006;6(1):37-46.
20. Traynor BJ, Codd MB, Corr B, Forde C, Frost E, Hardiman O. Amyotrophic lateral sclerosis mimic syndromes: a population-based study. Arch Neurol. 2000;57(1):109-113.

21. Mulder DW, Kurland LT, Offord KP, Beard CM. Familial adult motor neuron disease: amyotrophic lateral sclerosis. Neurology. 1986;36(4):511-517.

22. Li TM, Alberman E, Swash M. Comparison of sporadic and familial disease amongst 580 cases of motor neuron disease. J Neurol Neurosurg Psychiatry. 1988;51(6):778-784.

23. Johnston CA, Stanton BR, Turner MR, et al. Amyotrophic lateral sclerosis in an urban setting: a population based study of inner city London. J Neurol. 2006;253(12):1642-1643.

24. Worms PM. The epidemiology of motor neuron diseases: a review of recent studies. J Neurol Sci. 2001;191(1-2):3-9.

25. Chio A, Benzi G, Dossena M, Mutani R, Mora G. Severely increased risk of amyotrophic lateral sclerosis among Italian professional football players. Brain. 2005;128(Pt 3):472-476.

26. Horner RD, Grambow SC, Coffman CJ, et al. Amyotrophic lateral sclerosis among 1991 Gulf War veterans: evidence for a time-limited outbreak. Neuroepidemiology. 2008;31(1):28-32.

27. Wang H, O'Reilly EJ, Weisskopf MG, et al. Smoking and risk of amyotrophic lateral sclerosis: a pooled analysis of 5 prospective cohorts. Arch Neurol. 2011;68(2):207-213.

28. Abhinav K, Stanton B, Johnston C, et al. Amyotrophic lateral sclerosis in South-East England: a population-based study. The South-East England register for amyotrophic lateral sclerosis (SEALS Registry). Neuroepidemiology. 2007;29(1-2):44-48.

29. Vivekananda U, Manjalay ZR, Ganesalingam J, et al. Low index-toring finger length ratio in sporadic ALS supports prenatally defined motor neuronal vulnerability. J Neurol Neurosurg Psychiatry. 2011;82(6):635-637.

30. Manning JT, Scutt D, Wilson J, Lewis-Jones DI. The ratio of 2nd to 4th digit length: a predictor of sperm numbers and concentrations of testosterone, luteinizing hormone and oestrogen. Hum Reprod. 1998;13(11):3000-3004.

31. Berenbaum SA, Bryk KK, Nowak N, Quigley CA, Moffat S. Fingers as a marker of prenatal androgen exposure. Endocrinology. 2009;150(11):5119-5124

32. Chio A, Calvo A, Dossena M, Ghiglione P, Mutani R, Mora G. ALS in Italian professional soccer players: the risk is still present and could be soccer-specific. Amyotroph Lateral Scler. 2009;10(4):205-209.

33. Abel EL. Football increases the risk for Lou Gehrig's disease, amyotrophic lateral sclerosis. Percept Mot Skills. 2007;104(3 Pt 2): 1251-1254.

34. Paganoni S, Deng J, Jaffa M, Cudkowicz ME, Willis AM. Body mass index, not dyslipidemia, is an independent predictor of survival in amyotrophic lateral sclerosis. Muscle Nerve. 2011;44(1):20-24.

35. Hardiman O, van den Berg LH, Kiernan MC. Clinical diagnosis and management of amyotrophic lateral sclerosis. Nat Rev Neurol. 2011;7(11):639-649.

36. Lomen-Hoerth C. Amyotrophic lateral sclerosis from bench to bedside. Semin Neurol. 2008;28(2):205-211.

37. Cristini J. Misdiagnosis and missed diagnoses in patients with ALS. JAAPA. 2006;19(7):29-35.

38. Kiernan MC, Vucic S, Cheah BC, et al. Amyotrophic lateral sclerosis. Lancet. 2011;377(9769):942-955.

39. Forbes RB, Colville S, Swingler RJ. The epidemiology of amyotrophic lateral sclerosis (ALS/MND) in people aged 80 or over. Age Ageing. 2004;33(2):131-134.

40. McCombe PA, Henderson RD. Effects of gender in amyotrophic lateral sclerosis. Gend Med. 2010;7(6):557-570.

41. Andersen PM, Borasio GD, Dengler R, et al. EFNS task force on management of amyotrophic lateral sclerosis: guidelines for diagnosing and clinical care of patients and relatives. Eur J Neurol. 2005;12(12):921-938.

42. de Carvalho M, Dengler R, Eisen A, et al. Electrodiagnostic criteria for diagnosis of ALS. Clin Neurophysiol. 2008;119(3):497-503. 
43. Talbot K. Motor neuron disease: the bare essentials. Pract Neurol. 2009;9(5):303-309.

44. Dabby R, Lange DJ, Trojaborg W, et al. Inclusion body myositis mimicking motor neuron disease. Arch Neurol. 2001;58(8):1253-1256.

45. Weihl CC, Lopate G. Motor neuron disease associated with copper deficiency. Muscle Nerve. 2006;34(6):789-793.

46. Silani V, Messina S, Poletti B, et al. The diagnosis of amyotrophic lateral sclerosis in 2010. Arch Ital Biol. 2011;149(1):5-27.

47. Chio A. ISIS Survey: an international study on the diagnostic process and its implications in amyotrophic lateral sclerosis. J Neurol. 1999; 246 Suppl 3:III1-III5.

48. Davenport RJ, Swingler RJ, Chancellor AM, Warlow CP. Avoiding false positive diagnoses of motor neuron disease: lessons from the Scottish Motor Neuron Disease Register. J Neurol Neurosurg Psychiatry. 1996;60(2):147-151.

49. Ludolph AC, Knirsch U. Problems and pitfalls in the diagnosis of ALS J Neurol Sci. 1999;165 Suppl 1:S14-S20.

50. Rozen S, Cudkowicz ME, Bogdanov M, et al. Metabolomic analysis and signatures in motor neuron disease. Metabolomics. 2005;1(2):101-108.

51. Okamoto K, Mizuno Y, Fujita Y. Bunina bodies in amyotrophic lateral sclerosis. Neuropathology. 2008;28(2):109-115.

52. Leigh PN, Whitwell H, Garofalo O, et al. Ubiquitin-immunoreactive intraneuronal inclusions in amyotrophic lateral sclerosis. Morphology, distribution, and specificity. Brain. 1991;114(Pt 2):775-788.

53. Plaitakis A, Caroscio JT. Abnormal glutamate metabolism in amyotrophic lateral sclerosis. Ann Neurol. 1987;22(5):575-579.

54. Barbeito LH, Pehar M, Cassina P, et al. A role for astrocytes in motor neuron loss in amyotrophic lateral sclerosis. Brain Res Brain Res Rev. 2004;47(1-3):263-274.

55. Barbosa LF, Cerqueira FM, Macedo AF, et al. Increased SOD1 association with chromatin, DNA damage, p53 activation, and apoptosis in a cellular model of SOD1-linked ALS. Biochim Biophys Acta. 2010;1802(5):462-471.

56. Bilsland LG, Sahai E, Kelly G, Golding M, Greensmith L, Schiavo G. Deficits in axonal transport precede ALS symptoms in vivo. Proc Natl Acad Sci U S A. 2010;107(47):20523-20528.

57. King AE, Dickson TC, Blizzard CA, et al. Neuron-glia interactions underlie ALS-like axonal cytoskeletal pathology. Neurobiol Aging. 2011;32(3):459-469.

58. Zhu HN, Shi P, Wei YM, Zhang JY, Gal J. Mitochondrial dysfunction is a converging point of multiple pathological pathways in amyotrophic lateral sclerosis. J Alzheimers Dis. 2010;20 Suppl 2:S311-S324.

59. Miana-Mena FJ, Gonzalez-Mingot C, Larrode P, et al. Monitoring systemic oxidative stress in an animal model of amyotrophic lateral sclerosis. J Neurol. 2011;258(5):762-769.

60. Wuolikainen A, Moritz T, Marklund SL, Antti H, Andersen PM. Disease-related changes in the cerebrospinal fluid metabolome in amyotrophic lateral sclerosis detected by GC/TOFMS. PLoS One. 2011;6(4):e17947.

61. Talbot K. Do twin studies still have anything to teach us about the genetics of amyotrophic lateral sclerosis? J Neurol Neurosurg Psychiatry. 2010;81(12):1299-1300.

62. Garber K. Genetics. The elusive ALS genes. Science. 2008;319(5859):20.

63. Daoud H, Belzil V, Dion PA, Rouleau GA. Chromosome 9p21 in amyotrophic lateral sclerosis: the plot thickens. Lancet Neurol. 2010;9(10):945-947.

64. McCord JM, Fridovich I. Superoxide dismutase. An enzymic function for erythrocuprein (hemocuprein). J Biol Chem. 1969;244(22): 6049-6055.

65. van Es MA, Dahlberg C, Birve A, Veldink JH, van den Berg LH, Andersen PM. Large-scale SOD1 mutation screening provides evidence for genetic heterogeneity in amyotrophic lateral sclerosis. $J$ Neurol Neurosurg Psychiatry. 2010;81(5):562-566.

66. Marucci G, Morandi L, Bartolomei E, et al. Amyotrophic lateral sclerosis with mutation of the $\mathrm{Cu} / \mathrm{Zn}$ superoxide dismutase gene (SOD1) in a patient with Down syndrome. Neuromuscul Disord. 2007;17(9-10):673-676.
67. Hayward C, Brock DJ, Minns RA, Swingler RJ. Homozygosity for Asn86Ser mutation in the CuZn superoxide dismutase gene produces a severe clinical phenotype in a juvenile onset case of familial amyotrophic lateral sclerosis. J Med Genet. 1998;35(2):174.

68. Jonsson PA, Backstrand A, Andersen PM, et al. CuZn-superoxide dismutase in D90A heterozygotes from recessive and dominant ALS pedigrees. Neurobiol Dis. 2002;10(3):327-333.

69. Mancuso M, Filosto M, Naini A, et al. A screening for superoxide dismutase-1 D90A mutation in Italian patients with sporadic amyotrophic lateral sclerosis. Amyotroph Lateral Scler Other Motor Neuron Disord. 2002;3(4):215-218.

70. Gurney ME, Pu HF, Chiu AY, et al. Motor-neuron degeneration in mice that express a human $\mathrm{Cu}, \mathrm{Zn}$ superoxide-dismutase mutation. Science. 1994;264(5166):1772-1775.

71. Reaume AG, Elliott JL, Hoffman EK, et al. Motor neurons in $\mathrm{Cu} / \mathrm{Zn}$ superoxide dismutase-deficient mice develop normally but exhibit enhanced cell death after axonal injury. Nat Genet. 1996;13(1):43-47.

72. Shibata N, Hirano A, Kobayashi M, et al. Intense superoxide dismutase-1 immunoreactivity in intracytoplasmic hyaline inclusions of familial amyotrophic lateral sclerosis with posterior column involvement. J Neuropathol Exp Neurol. 1996;55(4):481-490.

73. Bruijn LI, Becher MW, Lee MK, et al. ALS-linked SOD1 mutant G85R mediates damage to astrocytes and promotes rapidly progressive disease with SOD1-containing inclusions. Neuron. 1997;18(2): 327-338.

74. Kato S, Shimoda M, Watanabe Y, Nakashima K, Takahashi K, Ohama E. Familial amyotrophic lateral sclerosis with a two base pair deletion in superoxide dismutase 1: gene multisystem degeneration with intracytoplasmic hyaline inclusions in astrocytes. $J$ Neuropathol Exp Neurol. 1996;55(10):1089-1101.

75. Zetterstrom P, Graffmo KS, Andersen PM, Brannstrom T, Marklund SL. Proteins that bind to misfolded mutant superoxide dismutase-1 in spinal cords from transgenic amyotrophic lateral sclerosis (ALS) model mice. J Biol Chem. 2011;286(23):20130-20136.

76. Watanabe M, Dykes-Hoberg M, Culotta VC, Price DL, Wong PC, Rothstein JD. Histological evidence of protein aggregation in mutant SOD1 transgenic mice and in amyotrophic lateral sclerosis neural tissues. Neurobiol Dis. 2001;8(6):933-941.

77. Wang J, Farr GW, Zeiss CJ, et al. Progressive aggregation despite chaperone associations of a mutant SOD1-YFP in transgenic mice that develop ALS. Proc Natl Acad Sci U S A. 2009;106(5):1392-1397.

78. Okamoto Y, Shirakashi Y, Ihara M, et al. Colocalization of 14-13-3 proteins with SOD1 in Lewy body-like hyaline inclusions in familial amyotrophic lateral sclerosis cases and the animal model. PLoS One. 2011;6(5):e20427.

79. Forsberg K, Jonsson PA, Andersen PM, et al. Novel antibodies reveal inclusions containing non-native SOD1 in sporadic ALS patients. PLoS One. 2010;5(7):e11552.

80. Forsberg K, Andersen PM, Marklund SL, Brannstrom T. Glial nuclear aggregates of superoxide dismutase-1 are regularly present in patients with amyotrophic lateral sclerosis. Acta Neuropathol. 2011;121(5):623-634.

81. Tainer JA, Getzoff ED, Richardson JS, Richardson DC. Structure and mechanism of copper, zinc superoxide dismutase. Nature. 1983;306(5940):284-287.

82. Parge HE, Hallewell RA, Tainer JA. Atomic structures of wild-type and thermostable mutant recombinant human $\mathrm{Cu}, \mathrm{Zn}$ superoxide-dismutase. P Natl Acad Sci U S A. 1992;89(13):6109-6113.

83. Bourne Y, Redford SM, Steinman HM, Lepock JR, Tainer JA, Getzoff ED. Novel dimeric interface and electrostatic recognition in bacterial Cu,Zn superoxide dismutase. P Natl Acad Sci U S A. 1996; 93(23):12774-12779.

84. Borgstahl GE, Parge HE, Hickey MJ, Beyer WF Jr, Hallewell RA, Tainer JA. The structure of human mitochondrial manganese superoxide dismutase reveals a novel tetrameric interface of two 4-helix bundles. Cell. 1992;71(1):107-118. 
85. Guan Y, Hickey MJ, Borgstahl GE, et al. Crystal structure of Y34F mutant human mitochondrial manganese superoxide dismutase and the functional role of tyrosine 34. Biochemistry. 1998;37(14):4722-4730.

86. Perry JJ, Hearn AS, Cabelli DE, Nick HS, Tainer JA, Silverman DN. Contribution of human manganese superoxide dismutase tyrosine 34 to structure and catalysis. Biochemistry. 2009;48(15):3417-3424.

87. Perry JJ, Shin DS, Getzoff ED, Tainer JA. The structural biochemistry of the superoxide dismutases. Biochim Biophys Acta. 2010;1804(2):245-262.

88. DiDonato M, Craig L, Huff ME, et al. ALS mutants of human superoxide dismutase form fibrous aggregates via framework destabilization. $J$ Mol Biol. 2003;332(3):601-615.

89. Shin DS, DiDonato M, Barondeau DP, et al. Superoxide dismutase from the eukaryotic thermophile alvinella pompejana: structures, stability, mechanism, and insights into amyotrophic lateral sclerosis. J Mol Biol. 2009;385(5):1534-1555.

90. Fan L, Fuss JO, Cheng QJ, et al. XPD helicase structures and activities: insights into the cancer and aging phenotypes from XPD mutations. Cell. 2008;133(5):789-800.

91. Wang Q, Johnson JL, Agar NY, Agar JN. Protein aggregation and protein instability govern familial amyotrophic lateral sclerosis patient survival. PLoS Biol. 2008;6(7):e170.

92. Vassall KA, Stubbs HR, Primmer HA, et al. Decreased stability and increased formation of soluble aggregates by immature superoxide dismutase do not account for disease severity in ALS. Proc Natl Acad Sci U SA. 2011;108(6):2210-2215.

93. Bystrom R, Andersen PM, Grobner G, Oliveberg M. SOD1 mutations targeting surface hydrogen bonds promote amyotrophic lateral sclerosis without reducing apo-state stability. $J$ Biol Chem. 2010;285(25):19544-19552.

94. Prudencio M, Hart PJ, Borchelt DR, Andersen PM. Variation in aggregation propensities among ALS-associated variants of SOD1: correlation to human disease. Hum Mol Genet. 2009;18(17):3217-3226.

95. Lindberg MJ, Tibell L, Oliveberg M. Common denominator of $\mathrm{Cu} /$ $\mathrm{Zn}$ superoxide dismutase mutants associated with amyotrophic lateral sclerosis: decreased stability of the apo state. Proc Natl Acad Sci USA. 2002;99(26):16607-16612.

96. Bosco DA, Morfini G, Karabacak NM, et al. Wild-type and mutant SOD1 share an aberrant conformation and a common pathogenic pathway in ALS. Nat Neurosci. 2010;13(11):1396-1403.

97. Proctor EA, Ding F, Dokholyan NV. Structural and thermodynamic effects of post-translational modifications in mutant and wild type $\mathrm{Cu}$, Zn superoxide dismutase. J Mol Biol. 2011;408(3):555-567.

98. Nishitoh H, Kadowaki H, Nagai A, et al. ALS-linked mutant SOD1 induces ER stress- and ASK1-dependent motor neuron death by targeting Derlin-1. Genes Dev. 2008;22(11):1451-1464.

99. Harraz MM, Marden JJ, Zhou W, et al. SOD1 mutations disrupt redox-sensitive Rac regulation of NADPH oxidase in a familial ALS model. J Clin Invest. 2008;118(2):659-670.

100. Kato S, Sumi-Akamaru H, Fujimura H, et al. Copper chaperone for superoxide dismutase co-aggregates with superoxide dismutase 1 (SOD1) in neuronal Lewy body-like hyaline inclusions: an immunohistochemical study on familial amyotrophic lateral sclerosis with SOD1 gene mutation. Acta Neuropathol. 2001;102(3): 233-238.

101. Urushitani M, Sik A, Sakurai T, Nukina N, Takahashi R, Julien JP. Chromogranin-mediated secretion of mutant superoxide dismutase proteins linked to amyotrophic lateral sclerosis. Nat Neurosci. 2006;9(1):108-118.

102. Kieran D, Hafezparast M, Bohnert S, et al. A mutation in dynein rescues axonal transport defects and extends the life span of ALS mice. J Cell Biol. 2005;169(4):561-567.

103. Zhang F, Strom AL, Fukada K, Lee S, Hayward LJ, Zhu H. Interaction between familial amyotrophic lateral sclerosis (ALS)linked SOD1 mutants and the dynein complex. J Biol Chem. 2007;282(22):16691-16699.
104. Da Cruz S, Cleveland DW. Understanding the role of TDP-43 and FUS/TLS in ALS and beyond. Curr Opin Neurobiol. 2011. 2011;21(6):904-919.

105. Polymenidou M, Lagier-Tourenne C, Hutt KR, et al. Long pre-mRNA depletion and RNA missplicing contribute to neuronal vulnerability from loss of TDP-43. Nat Neurosci. 2011;14(4):459-468.

106. Van Deerlin VM, Leverenz JB, Bekris LM, et al. TARDBP mutations in amyotrophic lateral sclerosis with TDP-43 neuropathology: a genetic and histopathological analysis. Lancet Neurol. 2008;7(5):409-416.

107. Kuhnlein P, Sperfeld AD, Vanmassenhove B, et al. Two German kindreds with familial amyotrophic lateral sclerosis due to TARDBP mutations. Arch Neurol. 2008;65(9):1185-1189.

108. Sreedharan J, Blair IP, Tripathi VB, et al. TDP-43 mutations in familial and sporadic amyotrophic lateral sclerosis. Science. 2008;319(5870):1668-1672.

109. Rutherford NJ, Zhang YJ, Baker M, et al. Novel mutations in TARDBP (TDP-43) in patients with familial amyotrophic lateral sclerosis. PLoS Genet. 2008:4(9):e1000193.

110. Kabashi E, Valdmanis PN, Dion P, et al. TARDBP mutations in individuals with sporadic and familial amyotrophic lateral sclerosis. Nat Genet. 2008;40(5):572-574.

111. Neumann M, Sampathu DM, Kwong LK, et al. Ubiquitinated TDP-43 in frontotemporal lobar degeneration and amyotrophic lateral sclerosis. Science. 2006;314(5796):130-133.

112. Arai T, Hasegawa M, Akiyama H, et al. TDP-43 is a component of ubiquitin-positive tau-negative inclusions in frontotemporal lobar degeneration and amyotrophic lateral sclerosis. Biochem Biophys Res Commun. 2006;351(3):602-611.

113. Maekawa S, Leigh PN, King A, et al. TDP-43 is consistently co-localized with ubiquitinated inclusions in sporadic and Guam amyotrophic lateral sclerosis but not in familial amyotrophic lateral sclerosis with and without SOD1 mutations. Neuropathology. 2009;29(6):672-683.

114. Mackenzie IR, Bigio EH, Ince PG, et al. Pathological TDP-43 distinguishes sporadic amyotrophic lateral sclerosis from amyotrophic lateral sclerosis with SOD1 mutations. Ann Neurol. 2007;61(5):427-434.

115. Vance C, Rogelj B, Hortobagyi T, et al. Mutations in FUS, an RNA processing protein, cause familial amyotrophic lateral sclerosis type 6 . Science. 2009;323(5918):1208-1211.

116. Neumann M, Mackenzie IR, Rademakers R. TDP-43 and FUS in amyotrophic lateral sclerosis and frontotemporal dementia. Lancet Neurol. 2010;9(10):995-1007.

117. Deng HX, Zhai H, Bigio EH, et al. FUS-immunoreactive inclusions are a common feature in sporadic and non-SOD1 familial amyotrophic lateral sclerosis. Ann Neurol. 2010;67(6):739-748.

118. Kwiatkowski TJ Jr, Bosco DA, Leclerc AL, et al. Mutations in the FUS/TLS gene on chromosome 16 cause familial amyotrophic lateral sclerosis. Science. 2009;323(5918):1205-1208.

119. Dormann D, Rodde R, Edbauer D, et al. ALS-associated fused in sarcoma (FUS) mutations disrupt Transportin-mediated nuclear import. EMBO J. 2010;29(16):2841-2857.

120. Snowden JS, Hu Q, Rollinson S, et al. The most common type of FTLD-FUS (aFTLD-U) is associated with a distinct clinical form of frontotemporal dementia but is not related to mutations in the FUS gene. Acta Neuropathol. 2011;122(1):99-110.

121. Neumann M, Bentmann E, Dormann D, et al. FET proteins TAF15 and EWS are selective markers that distinguish FTLD with FUS pathology from amyotrophic lateral sclerosis with FUS mutations. Brain. 2011;134(Pt 9):2595-2609.

122. Neumann M, Rademakers R, Roeber S, Baker M, Kretzschmar HA, Mackenzie IR. A new subtype of frontotemporal lobar degeneration with FUS pathology. Brain. 2009;132(Pt 11):2922-2931.

123. Woulfe J, Gray DA, Mackenzie IR. FUS-immunoreactive intranuclear inclusions in neurodegenerative disease. Brain Pathol. 2010;20(3):589-597.

124. Maruyama $\mathrm{H}$, Morino $\mathrm{H}$, Ito $\mathrm{H}$, et al. Mutations of optineurin in amyotrophic lateral sclerosis. Nature. 2010;465(7295):223-226. 
125. Swarup G, Nagabhushana A. Optineurin, a multifunctional protein involved in glaucoma, amyotrophic lateral sclerosis and antiviral signalling. J Biosci. 2010;35(4):501-505.

126. Zhu G, Wu CJ, Zhao Y, Ashwell JD. Optineurin negatively regulates TNFalpha- induced NF-kappaB activation by competing with NEMO for ubiquitinated RIP. Curr Biol. 2007;17(16):1438-1443.

127. Ying H, Shen X, Park B, Yue BY. Posttranslational modifications, localization, and protein interactions of optineurin, the product of a glaucoma gene. PLoS One. 2010;5(2):e9168.

128. Anborgh PH, Godin C, Pampillo M, et al. Inhibition of metabotropic glutamate receptor signaling by the huntingtin-binding protein optineurin. J Biol Chem. 2005;280(41):34840-34848.

129. Wild P, Farhan H, McEwan DG, et al. Phosphorylation of the autophagy receptor optineurin restricts Salmonella growth. Science. 2011;333(6039):228-233.

130. Ito HH, Fujita K, Nakamura M, et al. Optineurin is co-localized with FUS in basophilic inclusions of ALS with FUS mutation and in basophilic inclusion body disease. Acta Neuropathol. 2011;121(4):555-557.

131. Hortobagyi T, Troakes C, Nishimura AL, et al. Optineurin inclusions occur in a minority of TDP-43 positive ALS and FTLD-TDP cases and are rarely observed in other neurodegenerative disorders. Acta Neuropathol. 2011;121(4):519-527.

132. Deng HX, Bigio EH, Zhai H, et al. Differential involvement of optineurin in amyotrophic lateral sclerosis with or without SOD1 mutations. Arch Neurol. 2011;68(8):1057-1061.

133. Huang L, Huang Y, Guo H. Dominant expression of angiogenin in NeuN positive cells in the focal ischemic rat brain. $J$ Neurol Sci. 2009;285(1-2):220-223.

134. Greenway MJ, Andersen PM, Russ C, et al. ANG mutations segregate with familial and sporadic amyotrophic lateral sclerosis. Nat Genet. Apr 2006;38(4):411-413.

135. Wu D, Yu WH, Kishikawa $\mathrm{H}$, et al. Angiogenin loss-of-function mutations in amyotrophic lateral sclerosis. Ann Neurol. 2007;62(6) 609-617.

136. Prehn JH, Kieran D, Sebastia J, et al. Control of motoneuron survival by angiogenin. J Neurosci. 2008;28(52):14056-14061.

137. Hu GF, Kishimoto K, Liu SM, Tsuji T, Olson KA. Endogenous angiogenin in endothelial cells is a general requirement for cell proliferation and angiogenesis. Oncogene. 2005;24(3):445-456.

138. Crabtree B, Thiyagarajan N, Prior SH, et al. Characterization of human angiogenin variants implicated in amyotrophic lateral sclerosis. Biochemistry. 2007;46(42):11810-11818.

139. Hong SB, Siddique T. X-linked dominant locus for late-onset familial amyotrophic lateral sclerosis. Soc Neurosci Abst. 1998;24:478.

140. Lee T, Li YR, Ingre C, et al. Ataxin-2 intermediate-length polyglutamine expansions in European ALS patients. Hum Mol Genet 2011;20(9):1697-1700.

141. Fecto F, Siddique T. Making connections: pathology and genetics link amyotrophic lateral sclerosis with frontotemporal lobe dementia. J Mol Neurosci. 2011;45(3):663-675.

142. Kabashi E, Bercier V, Lissouba A, et al. FUS and TARDBP but not SOD1 interact in genetic models of amyotrophic lateral sclerosis. PLoS Genet. 2011;7(8):e1002214.

143. Mackenzie IR, Neumann M, Rademakers R, Roeber S, Baker M, Kretzschmar HA. A new subtype of frontotemporal lobar degeneration with FUS pathology. Brain. 2009;132:2922-2931.

144. Liu YH, Tian T. Hypothesis of optineurin as a new common risk factor in normal-tension glaucoma and Alzheimer's disease. Med Hypotheses. 2011;77(4):591-592.

145. del Toro D, Alberch J, Lazaro-Dieguez F, et al. Mutant huntingtin impairs post-Golgi trafficking to lysosomes by delocalizing optineurin/Rab8 complex from the Golgi apparatus. Mol Biol Cell. 2009;20(5):1478-1492.

146. Rezaie T, Child A, Hitchings R, et al. Adult-onset primary openangle glaucoma caused by mutations in optineurin. Science. 2002;295(5557):1077-1079.
147. Albagha OM, Visconti MR, Alonso N, et al. Genome-wide association study identifies variants at CSF1, OPTN and TNFRSF11A as genetic risk factors for Paget's disease of bone. Nat Genet. 2010;42(6): $520-524$

148. Shirakashi Y, Kawamoto Y, Tomimoto H, Takahashi R, Ihara M. Alpha-synuclein is colocalized with 14-13-3 and synphilin-1 in A53T transgenic mice. Acta Neuropathol. 2006;112(6):681-689.

149. van Blitterswijk M, Landers JE. RNA processing pathways in amyotrophic lateral sclerosis. Neurogenetics. 2010;11(3):275-290.

150. Gatchel JR,Zoghbi HY. Diseases of unstable repeat expansion: mechanisms and common principles. Nat Rev Genet. 2005;6(10):743-755.

151. Bourke SC, Tomlinson M, Williams TL, Bullock RE, Shaw PJ, Gibson GJ. Effects of non-invasive ventilation on survival and quality of life in patients with amyotrophic lateral sclerosis: a randomised controlled trial. Lancet Neurol. 2006;5(2):140-147.

152. Bowser R, Turner MR, Shefner J. Biomarkers in amyotrophic lateral sclerosis: opportunities and limitations. Nat Rev Neurol. 2011;7(11):631-638.

153. Kasai T, Tokuda T, Ishigami N, et al. Increased TDP-43 protein in cerebrospinal fluid of patients with amyotrophic lateral sclerosis. Acta Neuropathol. 2009;117(1):55-62.

154. Foulds P, McAuley E, Gibbons L, et al. TDP-43 protein in plasma may index TDP-43 brain pathology in Alzheimer's disease and frontotemporal lobar degeneration. Acta Neuropathol. 2008;116(2):141-146.

155. Wilson ME, Boumaza I, Lacomis D, Bowser R. Cystatin C: a candidate biomarker for amyotrophic lateral sclerosis. PLoS One. 2010;5(12):e15133

156. Ganesalingam J, An J, Shaw CE, Shaw G, Lacomis D, Bowser R Combination of neurofilament heavy chain and complement $\mathrm{C} 3$ as CSF biomarkers for ALS. J Neurochem. 2011;117(3):528-537.

157. Swash M. Early diagnosis of ALS/MND. JNeurol Sci. 1998;160 Suppl 1: S33-S36.

158. Bensimon G, Lacomblez L, Meininger V. A controlled trial of riluzole in amyotrophic lateral sclerosis. ALS/Riluzole Study Group. N Engl J Med. 1994;330(9):585-591.

159. Doble A. The pharmacology and mechanism of action of riluzole. Neurology. 1996;47(6 Suppl 4):S233-S241.

160. Garnock-Jones KP. Dextromethorphan/quinidine: in pseudobulbar affect. CNS Drugs. 2011;25(5):435-445

161. Rothstein JD, Patel S, Regan MR, et al. Beta-lactam antibiotics offer neuroprotection by increasing glutamate transporter expression. Nature. 2005;433(7021):73-77.

162. Izumi Y, Kaji R. Clinical trials of ultra-high-dose methylcobalamin in ALS. Brain Nerve. 2007;59(10):1141-1147.

163. Hemendinger RA, Armstrong EJ 3rd, Brooks BR. Methyl Vitamin B12 but not methylfolate rescues a motor neuron-like cell line from homocysteine-mediated cell death. Toxicol Appl Pharmacol. 2011;251(3):217-225

164. Cheah BC, Kiernan MC. Dexpramipexole, the $\mathrm{R}(+)$ enantiomer of pramipexole, for the potential treatment of amyotrophic lateral sclerosis. I Drugs. 2010;13(12):911-920.

165. Turner BJ, Talbot K. Transgenics, toxicity and therapeutics in rodent models of mutant SOD1-mediated familial ALS. Prog Neurobiol. 2008;85(1):94-134.

166. Swarup V, Julien JP. ALS pathogenesis: recent insights from genetics and mouse models. Prog Neuropsychopharmacol Biol Psychiatry. 2011;35(2):363-369.

167. Tudor EL, Galtrey CM, Perkinton MS, et al. Amyotrophic lateral sclerosis mutant vesicle-associated membrane protein-associated protein-B transgenic mice develop TAR-DNA-binding protein-43 pathology. Neuroscience. 2010;167(3):774-785.

168. Gordon PH, Meininger V. How can we improve clinical trials in amyotrophic lateral sclerosis? Nat Rev Neurol. 2011;7(11):650-654.

169. Kalmar B, Novoselov S, Gray A, Cheetham ME, Margulis B, Greensmith L. Late stage treatment with arimoclomol delays disease progression and prevents protein aggregation in the SOD1 mouse model of ALS. J Neurochem. 2008;107(2):339-350. 
170. Ralph GS, Radcliffe PA, Day DM, et al. Silencing mutant SOD1 using RNAi protects against neurodegeneration and extends survival in an ALS model. Nat Med. 2005;11(4):429-433.

171. Raoul C, Abbas-Terki T, Bensadoun JC, et al. Lentiviral-mediated silencing of SOD1 through RNA interference retards disease onset and progression in a mouse model of ALS. Nat Med. 2005;11(4):423-428.

172. Miller TM, Smith RA, Yamanaka K, et al. Antisense oligonucleotide therapy for neurodegenerative disease. J Clin Invest. 2006;116(8):2290-2296.

173. Takeuchi S, Fujiwara N, Ido A, et al. Induction of protective immunity by vaccination with wild-type apo superoxide dismutase 1 in mutant SOD1 transgenic mice. J Neuropathol Exp Neurol. 2010;69(10):1044-1056.

174. Hallewell RA, Laria I, Tabrizi A, et al. Genetically engineered polymers of human $\mathrm{CuZn}$ superoxide-dismutase. Biochemistry and serum half-lives. J Biol Chem. 1989;264(9): 5260-5268.

175. Tainer JA, Getzoff ED, Alexander H, et al. The reactivity of antipeptide antibodies is a function of the atomic mobility of sites in a protein. Nature. 1984;312(5990):127-134.

176. Tainer JA, Getzoff ED, Paterson Y, Olson AJ, Lerner RA. The atomic mobility component of protein antigenicity. Annu Rev Immunol. 1985;3:501-535.

177. Haidet-Phillips AM, Hester ME, Miranda CJ, et al. Astrocytes from familial and sporadic ALS patients are toxic to motor neurons. Nat Biotechnol. 2011;29(9):824-828.
178. Maragakis NJ, Lepore AC, Rauck B, et al. Focal transplantation-based astrocyte replacement is neuroprotective in a model of motor neuron disease. Nature Neuroscience. 2008;11(11):1294-1301.

179. Xu LY, Yan J, Chen D, et al. Human neural stem cell grafts ameliorate motor neuron disease in SOD-1 transgenic rats. Transplantation. 2006;82(7):865-875.

180. Charcot JM, Joffory A. Two cases of progressive muscular atrophy with lesions in the gray matter and in the anterolateral bundles of the spinal cord [Deux cas d'atrophie musculaire progressive avec lesions de la substance grise et des faisceaux anterolateraux de la moelle epiniere]. Arch Physiol Neurol Pathol 2. 1869:744-754. [French.]

181. Perry JJ, Fan L, Tainer JA. Developing master keys to brain pathology, cancer and aging from the structural biology of proteins controlling reactive oxygen species and DNA repair. Neuroscience. 2007;145(4):1280-1299.

182. Dormann D, Haass C. TDP-43 and FUS: a nuclear affair. Trends Neurosci. 2011;34(7):339-348.

183. ALS online genetics database. Available from: http://alsod.iop.kcl. ac.uk/als. Accessed December 28, 2011.

184. Genetic Association studies. Available from: http://www.alsgene.org. Accessed December 28, 2011.

185. ALS forum. Available from: http://www.researchals.org. Accessed December 28, 2011

186. Northeast ALS Consortium. Available from: http://www.alsconsortium. org. Accessed December 28, 2011.

187. ALS untangled. Available from: http://www.alsuntangled.com. Accessed December 28, 2011
Degenerative Neurological and Neuromuscular Disease

\section{Publish your work in this journal}

Degenerative Neurological and Neuromuscular Disease is an international, peer-reviewed, open access journal focusing on research into degenerative neurological and neuromuscular disease, identification of therapeutic targets and the optimal use of preventative and integrated treatment interventions to achieve improved outcomes, enhanced

\section{Dovepress}

survival and quality of life for the patient. The manuscript management system is completely online and includes a very quick and fair peer-review system. Visit http://www.dovepress.com/testimonials.php to read real quotes from published authors. 